\title{
Serogroups, serotypes and subtypes of Neisseria meningitidis isolated from patients and carriers in Greece
}

\author{
G. TZANAKAKI, C. C. BLACKWELL*, J. KREMASTINOU †, D. M. WEIR*, A. MENTIS and \\ R. J. FALLON $\ddagger$
}

National Meningitis Reference Laboratory, Hellenic Institute Pasteur, Athens, Greece, ${ }^{*}$ Department of Medical Microbiology, University of Edinburgh Medical School, Teviot Place, Edinburgh EH8 9AG, †Athens School of Public Health and $\$$ Meningococcal Reference Laboratory (Scotland), Ruchill Hospital, Glasgow

\begin{abstract}
Summary. The increase in the number of cases of meningococcal disease reported to the Ministry of Health in Athens since 1989 prompted the present study to determine if isolates from patients or carriers expressed the same phenotypic characters as those in other parts of Europe. None of the isolates from patients (31) or carriers (547) expressed the antigenic combinations associated with outbreaks in northern Europe, i.e., B:15:P1.16 or B:4:P1.15. The majority of the Greek isolates did not react with any of the six monoclonal serotype reagents tested; however, most reacted with one or more of the 11 monoclonal subtype antibodies. The results suggest that additional serotype reagents are needed for epidemiological studies in southeastern Europe and that vaccines based on serotype antigens developed against outbreak strains in northern Europe would not be effective in Greece.
\end{abstract}

\section{Introduction}

The increase in the number of cases of meningococcal disease reported to the Ministry of Health in Athens prompted the present study. ${ }^{1}$ As the last major epidemiological survey of Neisseria meningitidis in Greece was published in the 1970s before the availability of serotype and subtype reagents, ${ }^{2}$ the study had three main objectives: firstly, to determine whether the serotype and subtype reagents used in northern Europe and America can discriminate between isolates of meningococci from south-eastern Europe; secondly, to find out if serogroups, serotypes and subtypes of isolates from patients with meningococcal disease or carriers in northern Europe ${ }^{3-7}$ are prevalent among Greek isolates; and thirdly to see if particular phenotypes are associated with different regions of Greece.

\section{Materials and methods}

Thirty-one isolates from children aged 1 month-11 years with meningococcal disease were obtained from the microbiology laboratory of Aglaia Kyriakou Paediatric Hospital, Athens. The isolates were from sporadic cases that occurred during 1989-1991. Fiftyone isolates from school children aged 5-18 years who

Received 4 March 1992; accepted 21 April 1992.

*Correspondence should be sent to Dr C. C. Blackwell. were carriers were obtained in surveys undertaken in Athens between Dec. 1990 and Jan. $1991{ }^{8}$ A series of 496 isolates from military recruits aged 16-30 years were obtained during July 1990 and Jan. $1991^{1}$ within 3-5 days of the arrival of the recruits at the camps; recruits from all regions of Greece were represented.

The isolates were grown on modified New York City medium ${ }^{9}$ and characterised by Gram's stain, the oxidase test and by the rapid carbohydrate utilisation test (RCUT) ${ }^{10}$ Serogroups were determined by slide agglutination with polyclonal antisera to serogroups A, B, C, W135, X, Y and Z (Wellcome Diagnostics). Serotype and subtype were determined by a whole-cell enzyme-linked immunoassay (ELISA) with monoclonal antibody ${ }^{11}$ reagents supplied by $\operatorname{Dr}$ J.T. Poolman (RIVM, Bilthoven, The Netherlands).

Information obtained from each recruit regarding area of residence and socio-economic status was coded and entered into a Data Base 3 Plus program together with the results of the throat swab and the serogroup, serotype and subtype of the isolates. ${ }^{1}$ Similar data bases were prepared for information obtained from questionnaires returned by parents of school children participating in the surveys. ${ }^{8}$ Written informed consent was obtained from each of the recruits or from the parent or guardian of the children.

The results from the school children were compared with those obtained in a Scottish secondary school, where there was an outbreak of disease caused by a sulphonamide-resistant serogroup B serotype 4 subtype 15 (B:4:P1.15) strain, ${ }^{7}$ and results from the recruits were compared with published results for 133 
isolates obtained from carriers among Norwegian military recruits. ${ }^{6}$

\section{Results}

\section{Patients}

The antigenic phenotypes of isolates from patients are shown in table $I$. The most prevalent serogroup was B $(58 \%)$ followed by group C $(26 \%)$ and nongroupable isolates $(15 \%)$. The majority of isolates $(58 \%)$ did not react with any of the serotype antibodies. The most common serotype was $2 b$ ( 9 of 31 , $29 \%$ ) and the most common subtype was P1.10 (11 of $31.35 \%$ ). The most common serotype-subtype combination was $2 b: P 1.10$ (7 of $31,23 \%$ ).

\section{Carriers}

Among school children there was no predominant antigenic phenotype. Of the $19(37 \%)$ serogroupable isolates. 10 belonged to group $\mathrm{B}$. two to each of serogroups A. C, W135 and Y and one to group Z. As with the isolates from patients, the majority $(65 \%)$ did not react with any of the serotype antibodies; however. most $(75 \%)$ reacted with one or more subtype reagents. Two isolates $(4 \%)$ obtained from secondary school pupils expressed the $2 \mathrm{~b}: \mathrm{P} 1.10$ combination found among those from patients (tables II and III).

Of the 496 isolates from recruits, $36 \%$ were serogroupable: $24 \%$ were group B. $5 \%$ group C and $4 \%$ group A. Most isolates $(69 \%)$ were not serotypable. but $64 \%$ reacted with one or more of the subtype antibodies. The most common serotype was $14(16 \%)$, and the most common subtype was P1.2(16\%) (tables II and III). The most prevalent combination of serotype-subtype antigens was $14: \mathrm{Pl} .2(n=24)$ followed by $14: \mathrm{Pl} .7(n=13)$. None of the isolates from the recruits expressed the $2 \mathrm{~b}: \mathrm{P} 1.10$ combination predominant among children with meningococcal disease. None of the $2 a$ or $2 b$ isolates from carriers reacted with any of the subtype antibodies.

\section{Geographic areas}

The major regions of Greece are shown in the figure together with the proportion of recruits from whom meningococci were isolated. Meningococci were obtained most frequently from recruits from the northeast of Greece: Thrace ( $37 \%$ ). West Macedonia (33\%) and East Macedonia ( $30 \%$ ). Because military service is compulsory. even for individuals who live abroad. there were 33 subjects who were not normally resident in Greece. Among these, 33\% were carriers.

There were no unusual distributions of serogroups among the different regions. The most common serotype (14) was found in equal proportions $(15 \%)$ among the isolates from the two major centres of
Table I. Antigenic phenotypes of isolates from children with meningococcal disease

\begin{tabular}{|c|c|}
\hline Antigenic phenotype & $\begin{array}{l}\text { Number } \\
\text { of isolates }\end{array}$ \\
\hline B:-:- & 3 \\
\hline B :-: P1.1 & 1 \\
\hline B :-: P1.9 & 4 \\
\hline B:-:P1.10 & 2 \\
\hline B:-:Pl.14 & 1 \\
\hline B:2b:P1.9 & 1 \\
\hline $\mathrm{B}: 2 \mathrm{~b}: \mathrm{P} 1.10$ & 4 \\
\hline B: $14: P 1.15$ & 1 \\
\hline B: $15: P 1.6$ & 1 \\
\hline$C:-: P 1.6$ & 2 \\
\hline$C:-: P 1.10$ & 3 \\
\hline C:-:P1.14 & 1 \\
\hline$C:-: P 1.16$ & 1 \\
\hline $\mathrm{C}: 2 \mathrm{~b}: \mathrm{P} 1.2$ & 1 \\
\hline $\mathrm{NG}: 2 \mathrm{a}: \mathrm{P} 1.6$ & 1 \\
\hline $\mathrm{NG}: 2 \mathrm{~b}: \mathrm{P} 1.10$ & 3 \\
\hline NG:14:P1.10 & 1 \\
\hline
\end{tabular}

Table II. Comparison of serotypes of isolates from carriers in Greece with those from carriers in northern Europe

\begin{tabular}{lcccc}
\hline & \multicolumn{4}{c}{ Percentage of isolates from } \\
\cline { 2 - 5 } Serotype & \multicolumn{2}{c}{ recruits } & school children \\
\cline { 2 - 5 } & $\begin{array}{c}\text { Greece } \\
(n=485)\end{array}$ & $\begin{array}{c}\text { Norway } \\
(n=133)\end{array}$ & $\begin{array}{c}\text { Greece } \\
(n=51)\end{array}$ & $\begin{array}{c}\text { Scotland } \\
(n=121)\end{array}$ \\
\hline 1 & 4 & 5 & 8 & 9 \\
$2 \mathrm{a}$ & 1 & 5 & 6 & 0 \\
$2 \mathrm{~b}$ & 5 & 0 & 8 & 5 \\
4 & 2 & 22 & 8 & 36 \\
$8^{*}$ & $\ldots$ & 8 & $\ldots$ & $\ldots$ \\
14 & 16 & 16 & 2 & 13 \\
15 & 3 & 8 & 4 & 8 \\
$21^{*}$ & $\ldots$ & 8 & $\ldots$ & 7 \\
Non-typable & 69 & 28 & 64 & 22 \\
\hline
\end{tabular}

*Not tested in this study.

Table III. Comparison of subtypes of isolates from carriers in Greece with those from carriers in northern Europe

\begin{tabular}{|c|c|c|c|c|}
\hline \multirow{3}{*}{ Subtype } & \multicolumn{4}{|c|}{ Percentage of isolates from } \\
\hline & \multicolumn{2}{|c|}{ recruits } & \multicolumn{2}{|c|}{ school children } \\
\hline & $\begin{array}{c}\text { Greece } \\
(n=489)\end{array}$ & $\begin{array}{c}\text { Norway } \\
(n=133)\end{array}$ & $\begin{array}{c}\text { Greece } \\
(n=51)\end{array}$ & $\begin{array}{l}\text { Scotland } \\
(n=121)\end{array}$ \\
\hline Pl.1 & 9 & 5 & 14 & 3 \\
\hline P1.2 & 16 & 16 & 8 & 17 \\
\hline $\mathrm{Pl} .3^{*}$ & & 13 & & 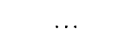 \\
\hline $\mathrm{Pl} .4$ & 1 & 0 & 0 & 0 \\
\hline Pl.6 & 6 & 0 & 8 & 8 \\
\hline P1.7 & 6 & 0 & 4 & 7 \\
\hline P1.9 & 9 & 0 & 18 & 0 \\
\hline P1.10 & 6 & 0 & 10 & 0 \\
\hline Pl.12 & 2 & () & 4 & 0 \\
\hline P1.14 & 2 & 0 & 0 & 0 \\
\hline P1.15 & 4 & 19 & 8 & 23 \\
\hline P1.16 & 3 & 8 & 0 & 4 \\
\hline Non-typable & 36 & 39 & 26 & 38 \\
\hline
\end{tabular}

*Not tested in this study. 


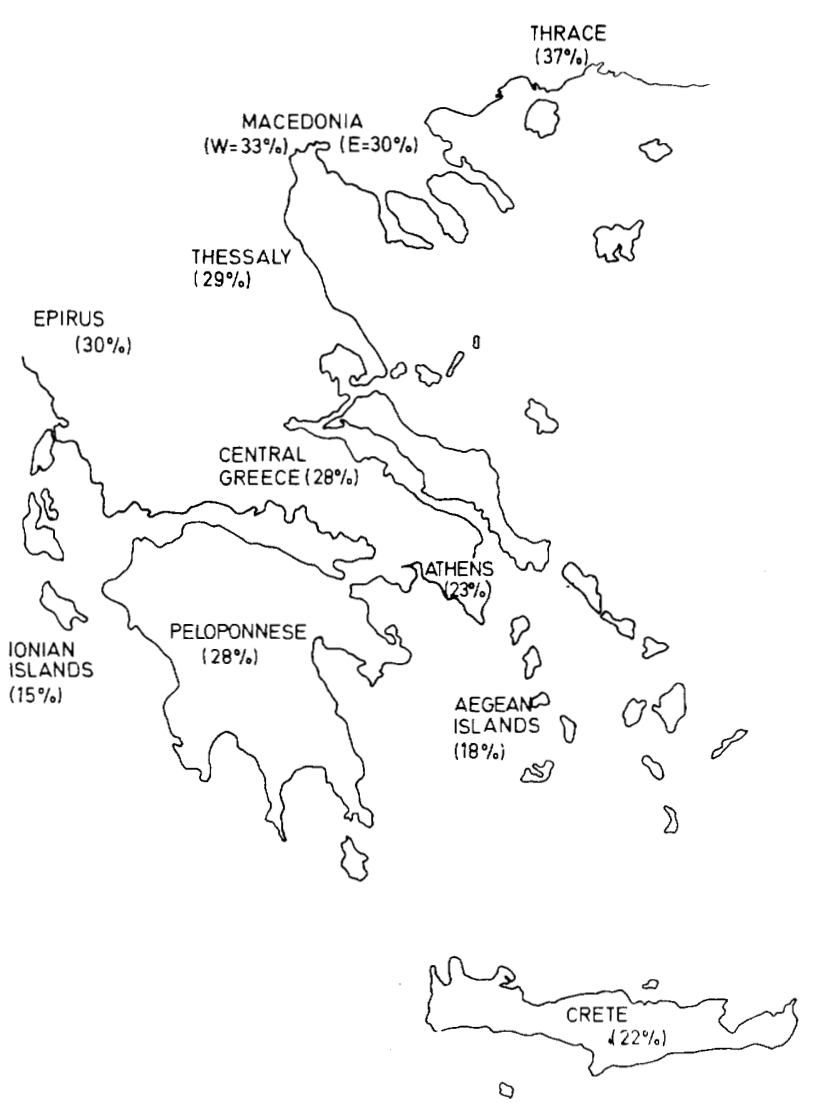

Figure. Proportion of carriers among recruits from different regions of Greece.

population, greater Athens and East Macedonia. Over $20 \%$ of the isolates from Thessaly $(22 \%)$, the Peloponnese $(21 \%)$, Crete $(25 \%)$ and the Aegean Islands $(30 \%)$ expressed the type 14 antigen.

Isolates representative of all the 11 subtypes examined were found among those from recruits from greater Athens, East Macedonia and Crete. More isolates that did not react with the subtype antibodies were obtained from recruits from the north of Greece: Thrace, Macedonia and Epirus.

\section{Discussion}

The first two objectives of the study were to determine if the serotype and subtype reagents used for epidemiological studies in northern Europe and the Americas could be used in epidemiological studies in Greece, and if the serotype and subtype combinations associated with disease in other populations were found in Greece. The proportion of non-serotypable isolates from the Greek recruits $(69 \%)$ and school children $(64 \%)$ was greater than the proportion of non-serotypable isolates obtained from carriers among Norwegian recruits $(28 \%)^{6}$ or Scottish school children $(22 \%)$. The proportion of serotype 14 isolates was similar for Greek (16\%) and Norwegian (16\%) recruits and Scottish school children $(13 \%)$ but was much lower $(2 \%)$ among Greek children. The proportion of $2 b$ serotypes was similar for the Greek recruits and Scottish school children. Serotype 4 was the most prevalent type among the Norwegian $(22 \%)^{6}$ and Scottish $(36 \%)$ isolates compared with $2-8 \%$ of the Greek isolates. Serotype 15 was found in $8 \%$ of isolates from north Europeans compared with 3-4\% of the Greek isolates. This suggests that other serotype reagents need to be developed for epidemiological studies of meningococci from Greece and that the serotypes associated with recent outbreaks in Britain and Scandinavia are uncommon in Greece.

The proportion of isolates from the Greek recruits $(36 \%)$ and school children $(26 \%)$ that did not react with any of the subtype reagents was similar to that of isolates from the Norwegian recruits $(39 \%)^{6}$ and from Scottish school children $(38 \%)$. The proportion of subtype P1.2 isolates was similar for Greek $(16 \%)$ and Norwegian (16\%) recruits and Scottish school children $(17 \%)$ but was lower among Greek school children $(8 \%)$. The proportion of subtype P1.15 was similar among the Norwegian $(19 \%)^{6}$ and Scottish $(23 \%)$ isolates but was greater than that found in the Greek isolates (4-8\%). The subtype reagents appear to discriminate between strains from Greek carriers as effectively as between carrier strains from northern Europe; however, the proportions of subtypes associated with outbreaks in northern Europe are lower.

Combinations of serotype and subtype antigens $15: \mathrm{P} 1.16,4: \mathrm{P} 1.15$ and $2 \mathrm{a}: \mathrm{P} 1.2$ associated with outbreaks in northern Europe ${ }^{4,5}$ were not found among any of the isolates in this study. Although P1.2 was the most common subtype found in the study there was only one patient isolate with this subtype, $\mathrm{C}: 2 \mathrm{~b}: \mathrm{P} 1.2$ (table I). In contrast, the $2 \mathrm{a}: \mathrm{P} 1.2$ and $2 \mathrm{~b}: \mathrm{P} 1.2 \mathrm{com}-$ binations are found frequently among Scottish group $\mathrm{C}^{12}$ and French serogroup B isolates and $2 \mathrm{a}: \mathrm{P} 1.2$ is found frequently among French serogroup $\mathrm{C}$ isolates. ${ }^{13}$ The only report of meningococcal serotypes from southeast Europe is that of the C:2a phenotype associated with disease in Italy. ${ }^{14}$ None of the serogroup $\mathrm{C}$ isolates expressed this serotype.

The third objective was to determine if there were antigenic phenotypes associated with different areas of Greece, e.g., those in which there are large numbers of foreign tourists or foreign military personnel or areas such as the northeast were there is a significant Muslim population some of which might have visited Saudi Arabia; however, there was no unusual distribution of serogroups or serotypes in the different regions of Greece.

The results of the study suggest that vaccines based on serotypes and subtype combinations associated with disease in northern Europe such as the one being developed and tested in Norway will not be appropriate for Greece. 


\section{References}

1. Blackwell CC. Tzanakaki G. Kremastinou J et al. Factors affecting carriage of Neisseria meningitidis among Greek military recruits. Epidemiol Infect 1992; 108 : 441-448.

2. Kalapothaki V. Vassilliadis P. Trichopoulos D, Kaklamani E. Sérié C. Caractéristiques séro-épidémiologiques chez les porteurs sains de Méningocoques en Grèce. Ann Micriobiol (Institut Pasteur) 1979: 130B: 43 54.

3. Poolman JT, Jonsdottir K. Jones DM. Lind I. Frøholm LO. Zanen HC. Meningococcal serotypes and serogroup B disease in North-West Europe. Lancet 1986: 2: 555-558.

4. Poolman JT. Meningococcal vaccines. J Med Microbiol 1988: 26: $170-172$

5. Abdillahi H. Poolman JT. Typing of group-B Neisseria meninyitidis with monoclonal antibodies in whole-cell ELISA. J Med Microbiol 1988: 26: 177-180.

6. Wedege E. Hoiby EA. Rosenquist ER. Froholm LO. Serotyping and subtyping of Neisseria meningitidis isolates by coagglutination. dot-blotting and ELISA $J$ Med Microbiol 1990:31: 195201

7. Blatekwell CC. Weir DM. James VS et al. Secretor status, smoking and carriage of Neisseria meningitidis. Epidemiol Infect 1990: 104: 203-209.
8. Blackwell CC, Tzanakaki G, Kremastinou J et al. Carriage of Neisseria meningitidis among school children in Athens. Abstracts of the 120th Meeting of the Society for General Microbiology 1991

9. Young H. Cultural diagnosis of gonorrhoea with modified New York City (MNYC) medium. Br J Vener Dis 1978; 54 3640.

10. Young H, Paterson IC, McDonald DR. Rapid carbohydrate utilization test for identification of Neisseria gonorrhoeae. Br J Vener Dis 1976; 52: 172-175.

11. Abdillahi H. Poolman JT. Whole-cell ELISA for typing Neisseria meningitidis with monoclonal antibodies. FEMS Microbiol Lett 1987: 48: 367-371.

12. Fallon RJ. Meningococcal infections in Scotland 1990. Communicable Diseases and Environmental Health in Scotland Weekly Report 1991; 25: $91 / 25.49$

13. Riou JY Poolman JT, Auriol J, Lamprez F, Guibourdenche M Serosubtyping of group B, C, Y and A meningococci isolated in France in 1988. Ann Biol Clin (Paris) 1989; 48: 227-231.

14. Mastrantonio P, Congiu ME, Occhionero M, Stroffolini T. Genomic fingerprints and phenotypic characteristics of strains of Neisseria meningitidis causing disease in Italy. Microbiologica 1990; 13: 109-113. 